\title{
Managing Science and Technology Occupations of Women in Nigeria
}

\author{
Aderemi, H. O.', Hassan, O. M.2, Siyanbola, W. O. ${ }^{3}$, Taiwo, K. ${ }^{4}$
}

\begin{abstract}
The study examined the occupational activities of female graduates in science and technology related fields with a view to assessing factors influencing their performance and make recommendations to enhance women work experiences in S\&T occupations. The data for the study was collected through questionnaire and interview schedule from a sample of 2110 respondents comprising of employed female Science and Technology (S\&T) graduates and heads of departments in tertiary institutions and S\&T firms in Nigeria. The study reveal that most female S\&T graduates (FSTGs) employed in tertiary institutions and research institutions were engaged in S\&T based occupations. However, in corporate firms, most of the FSTGs work either in administration, finance or R\&D departments. In addition, a large proportion takes less paying non S\&T jobs for domestic reasons and lack of suitable vacancies. This suggests gross under-utilization of human resource. Some S\&T organizations did not have any female working in S\&T departments. Recommendations were made to enhance the recruitment, retention and performance of women in S\&T employment in Nigeria.
\end{abstract}

Keywords: Science and technology; occupations; women; female; post-graduation; Nigeria.

\footnotetext{
${ }^{1}$ National Centre for Technology Management, Obafemi Awolowo University, Ile-lfe, Nigeria helen.aderemi@nacetem.org

${ }^{2}$ National Centre for Technology Management, Obafemi Awolowo University, Ile-lfe, Nigeria reachaoh@yahoo.co.uk

${ }^{3}$ National Centre for Technology Management, Obafemi Awolowo University, lle-Ife, Nigeria wsybola@yahoo.com

${ }^{4}$ Department of Food Science and Technology, Obafemi Awolowo University, Ile-lfe, Nigeria kehindetaiwo3@yahoo.com
}

ISSN: 07I8-2724. (http://www.jotmi.org)

Journal of Technology Management \& Innovation (C) Universidad Alberto Hurtado, Facultad de Economía y Negocios 


\section{Introduction}

A number of studies have shown that women's employment is heavily concentrated in a few occupations. They work typically as home and farm helpers, nurses, lower-school teachers, secretaries among others. Issues of gender mainstreaming have also led to advance studies and women participation in S\&T. It is necessary not only to understand and indicate statistically how female S\&T enrollments and graduation situations differ from those of men; but to understand how women also fared in employments in S\&T professions. Brain drain discussions have led to the increased awareness of untapped human resources for S\&T in general and women in particular. The benefit that would accrue to national S\&T and sustainable development if women's talents and knowledge were taken advantage of should be understood. Employers who therefore insist on recruiting men only do so from a shrinking recruitment pool. Bound up with changing trends in the employment market are employers' changing attitudes to human resource management. As part of the move towards total quality management and in pursuit of quality standards such as investments in people, top business leaders are increasingly recognizing and publicly acknowledging the difference a highly skilled workforce can contribute to the performance, effectiveness and competitiveness of an organization. As a result the recruitment, retention and development of the most talented people in the workforce, including women, has become a keen topic for consideration. However, when there is a mass exclusion of a group of people whether intentional or coincidental - with a different set of perspectives and worldviews, the profession is the poorer. In recent years, another compelling reason for employers to pay greater attention to the female workforce is the awareness that women are increasingly skilled and better educated, and account for almost half of University graduates.

Over the years, many different task forces in the US have voiced concern about the number of women faculty members in engineering and science. Those voices began to be heard through the Women in Science and Engineering (WISE) coalition, which challenged major research Universities in the Midwest to develop action plans. Although there is little data available on women's participation in science and technology at the postgraduation levels in Nigeria, it is nonetheless clear that sweeping generalizations based on identified trends and simplistic conclusions will be of little value in increasing women's participation in national S\&T. For instance, there is a general belief that employers of labour in the Nigeria financial sector prefer to employ graduates of S\&T on the grounds that these graduates perform better with mathematical computations of figures. It is hoped, however, that this study will throw more light on the employment trend of S\&T graduates in all sectors of the economy.

\section{Literature review}

S\&T is often not considered an appropriate occupation for girls and women, for reasons ranging from lack of intellectual ability to expectations that women work inside the home. A professional double standard persists when women's ability and achievements are assessed. Often, women are not 'allowed' to possess the same personality traits, which are considered important for male success in the work environment. For example, while competitiveness, aggressiveness and a certain amount of self-promotion are considered acceptable and even necessary traits for a successful man, the same behaviour in women is considered 'pushy' and inappropriate. Women's reproductive responsibilities clash with their professional responsibilities. The child-bearing and intensive child-rearing years coincide with important years for gaining tenure. This is one reason that women tend to be older than their male colleagues at the same level (if they reach that level). It is frequently the women who sacrifice their education and career for the sake of the family. Those women who are supported by family or paid help to continue their careers can encounter other obstacles. Gender-role stereotyping is a major barrier for women, whether it manifests in the home, science classroom, research laboratory or the engineering and technology workplace (Armour, 2003). A study carried out in Europe (Bruyas and Drioli, 1997) found out that stereotypes and standards put forward by society as well as opinions of peer groups have inhibited many women from taking up science and technology careers. Marasco (2005) identified among others a relative lack of 
professional and educational support systems and workfamily conflicts as barriers to women success both in education and employment.

McGregor and Harding (1996) carried out a study that showed that women have greater difficulty entering science and technology professions, they receive fewer promotions, and they have less access to supervisory positions. A study of women scientists in the United Kingdom reveal that women are still unrepresented in the higher echelons of U.K. science, engineering, and technology and limited in their opportunities for advancement (Ellis, 2003). The author attributes this to the organization and structure of scientific work and conflict with childbearing and child raising. In addition, Kishore, 2008 reported on the dismally low representation of women in technology-related enterprises and institutes of higher education in technology in India. In Australia, women make up about $51 \%$ of the population, which is similar to that of Nigeria. For this reason, the Women in Science, Engineering and Technology Advisory Group believes that continued under-representation and under-participation of women in SET (Science, Education and Technology)-based education, training and employment is not only a cause for social concern on equity grounds, it is also likely to inhibit Australia's capacity to develop internationally competitive research and industries (Australian Science and Technology Heritage Centre, 2003).

Thus, there seems to be a general recognition of the value and inadequacy of women in S\&T professions. And to this end, government of different countries make attempt at providing interventions to enhance women's participation in S\&T education and employments. Girls are been encouraged to take up science and technology courses in schools. The question then arises- what happens after these girls have been trained and have graduated? This study attempts to unveil the post-graduation occupation of females trained in S\&T and proffer how the society can maximally benefit from their training.

\section{Methodology}

\section{Participants}

The Sample which was purposively selected from the six geo-political zones of Nigeria consisted of 2, 110 Heads of S\&T firms, employed female graduates, and Heads of Department in tertiary institutions with a total response rate of $81.4 \%$. Furthermore, selected key firms within each engineering sub-sector, which include: Chemical, Computer, Electrical, Civil, Mechanical, Metallurgical, Food Science and Agricultural Engineering were visited in each zone as well as financial institutions such as Auditing firms, Banks, Insurance Companies and Financial Houses to determine the number and performance of female S\&T graduates employed in their establishments. Interviews were conducted with some of the female graduates and their employers or supervisors in the institutions and firms visited.

\section{Design}

Structured questionnaire and on-one interview was the instrument employed for the survey. The survey instrument was pre-tested in a pilot test to validate the questionnaires before it was used for the main survey.

\section{Procedure}

To explore in depth the experience of women currently employed in the relevant sectors and to understand their career paths, working conditions and attitudes; questions were asked on socio-economic characteristics, education, career, employments and challenges. Also to assess the factors influencing the performance of women in S\&T occupations, measures of performance and management practices in different sectors as set out by the Nigerian Universities Commission, National Board for Technical Education, Civil Service Rules and Private Organizations were considered as appropriate. The one-on-one interview on the employees and employers was to give insight into performance challenges, policies in the institutions and recommendation towards enhancing the participation of women in S\&T institutions. The information that was gathered were sorted, edited and coded. The Statistical Package for Social Sciences (SPSS) and Excel was used for data analyses. A quantitative method of analyses specifically descriptive statistics was used. Among the descriptive statistical techniques were frequencies, means, percentages and cross tabulations.

\section{Results}

\section{Socio-economic Characteristics}

The largest proportion (42.5\%) of the FSTG was aged between 20 and 30 years followed by $39.2 \%$ in the $31-40$ 
years bracket. About $15.5 \%$ of the respondents were aged between $4 \mathrm{I}$ and 50 years, while only $2.8 \%$ were above 50 years. This result suggests that most of the respondents were young with about $81.7 \%$ less than 40 years old.

\section{Marital Status}

As at the survey time, about $40.2 \%$ of the respondents were single, while $52.9 \%$ were married. Other respondents were either separated $(2.6 \%)$, divorced $(2.4 \%)$ or widowed (2.0\%) all totaled about less than $10 \%$. Further analysis showed that $73.1 \%$ of the single respondents were aged between 20 and 30 years, while a similar percentage of those in age bracket 3I-40 and 4I-50 were married. Respondents that were separated, divorced or widowed were aged $4 \mathrm{I}$ years and above.

For the married respondents, $62.7 \%$ of the spouses were Civil Servants, $19 \%$ work in private organizations, while about $16 \%$ were self-employed. Only a small proportion of the spouses $(2.3 \%)$ were clergy men. This result shows that with about $80 \%$ of the spouse being not self employed, mobility of the FSTGs would be highly linked or restricted by that of the husband.

\section{Number of Children}

Data on the number of children of FSTG revealed that a large number of respondents (45\%) have either 2 or 3 children, $21.7 \%$ have only one child and $3.4 \%$ have four or more children. Further analysis of age of respondents and number of children showed that $50 \%$ of FSTGs who had only one child were aged between 20 and 30 years, while those who have 2-3 children were between 31 and 40 years of age. Among the FSTG aged between $4 \mathrm{I}-50$ and above, only $4.2 \%$ had only one child, $39.1 \%$ had $2-3$ children and $45.6 \%$ had $4-5$, while $11.2 \%$ had more than 5 children. Thus $56.8 \%$ of the older FSTGs (>4I years) have more than four children. The younger respondents have less number of children and this may have implication for job performance.

\section{Educational Accomplishment and Information on Undergraduate Studies}

Tertiary Institutions Attended, Degrees Obtained and Class of Degree of FSTGs

A high proportion of the FSTGs (68.5\%) had at least a first degree from the University. Of the 1345 respondents, $68.8 \%$ were graduates of Universities, $23.7 \%$ were graduates of Polytechnics, while $7.4 \%$ finished from Colleges of Education with the National Certificates of Education (NCE). Of the Polytechnic graduates, 14.2\% obtained the Higher National Diploma (HND) certificates, while $6.0 \%$ received the Ordinary National Diploma (OND) Certificates. Among the University FSTGs about $10.4 \%$ graduated with a First Class Honors degree, $49 \%$ had Second Class Upper Division, 35.8\% Second Class Lower Division and about 4.8\% a Third Class. Amongst the FSTG of Polytechnics, 53.5\% graduated with Upper Credit, $44.8 \%$ had Lower Credit and only $1.7 \%$ graduated with a Pass certificate. This result indicates that the women not only have the ability to study S\&T courses, but also performed excellently.

\section{Courses Studied}

S\&T courses were grouped into the following broad areas: Science (Biology, Biochemistry, Botany, Zoology, Geology, Engineering Physics, Mathematics, Chemistry, Physics), Engineering (Chemical Engineering, Civil Engineering, Electrical and Electronics Engineering, Computer Engineering, Mechanical Engineering), Environmental Design and Management (EDM - Urban and Regional Planning, Quantity Survey, Architecture, Building, Town Planning, Estate Management), Agriculture (Plant Science, Soil Science, Animal Science, Agricultural Economics, Extension and Rural Sociology) and Education (Science Education courses). Of these disciplines, the highest proportion of respondents studied science courses (61.4\%) followed by $23.5 \%$ who studied engineering courses. Science courses in EDM, Agriculture and Education were studied by $6.2 \%, 7.4 \%$ and $1.5 \%$ respectively. These results indicate that science and engineering courses are highly sought after by female secondary school leavers. The comparative small number of female students studying courses in EDM, Agriculture and or Education could be due to poor awareness of the potential job opportunities or that these groups of respondents were not readily available during the survey.

Respondents were asked if the courses studied were the original courses of interest for which they applied for admission. Results showed that about $\mathbf{7 4 . 3 \%}$ of the FSTGs were given admission to study their preferred courses. However, $25.7 \%$ responded in the negative. The University 
admission process allows for an applicant to be offered admission in courses other than those applied for as long as the subject criteria and qualification criteria are met. When students are compelled to study what was not their primary choice of course, their attitude to work and academic performance are sometimes affected. Some respondents that studied science courses would have preferred courses in Administration and the Humanities. The larger percentage $(76.6 \%)$ would still have wanted courses in S\&T and the professional courses like Medicine, Pharmacy, Engineering and Science in that order. Agriculture is the least desired S\&T course and this is due to the poor perception of agriculture as not being a prestigious course.

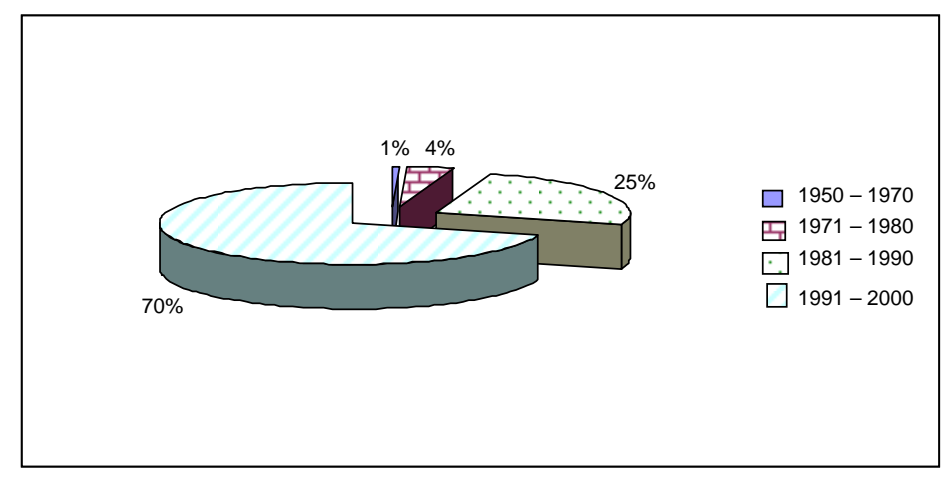

Figure I. Year of Graduation of FSTG

Figure I show the year of graduation of the respondents. The number of females studying S\&T has increased tremendously over the years with $70 \%$ of the respondents graduating between 1990 and 2000. This suggests an increased awareness amongst female secondary school pupils and the interest and capability to cope or excel in these courses as affirmed by the Class of degrees obtained at the tertiary level.

\section{Post-graduation Occupation of Female S\&T Graduates}

Two broad categories of responses are discussed in this section, which are: i) Employers' responses in Firms and Tertiary Institutions and ii) FSTG's responses in Firms and Tertiary Institutions.

\section{Employers' Reponses: Employments of FSTG in Firms}

The study revealed that about $57.1 \%$ employments of FSTGs are in the manufacturing and engineering sector of the economy. This percentage was scantily distributed in between the various sectors. For instance, $11.2 \%$ employment of FSTGs took place in engineering firms, food and beverage firms had $5.1 \%$, chemicals and Pharmaceuticals had 1\%. Comparatively many (15\%) women in S\&T seemed to have entered the field of ICT unlike engineering and chemical firms. This is probably due to the popularity and huge investments that the industry has gained in recent times. Finance organizations employ a significant percentage $(32.7 \%)$ of the female graduates. Research Institutions had a lower employment of $10.2 \%$ when compared to finance and engineering firms. This suggests that so many women were not involved in Research and Development activities in the country.

\section{Employers' Responses on Employment of FSTG in Tertiary Institutions}

The highest qualification of S\&T workforce in the tertiary institutions was doctoral degree (Ph.D). While $71.4 \%$ of the males have Ph.D, only $28.6 \%$ of females possessed this qualification. A Ph.D as the highest qualification was expected following from the academic nature of the environment. However, the number of workers with master degree (M. Sc.) was higher with $61.3 \%$ of them being males and $38.7 \%$ females. In all the categories, females were lower in number. This result confirms previous works that the number of women in tertiary level S\&T education and in S\&T professions is low around the world. Other qualifications of the S\&T workforce included B.Sc. (males $63.4 \%$ and females $39.6 \%$ ), HND (males $71.6 \%$ 
and females 28.4\%), OND (males $60.0 \%$ and females 40.0\%), C\&G (males $63.6 \%$ and females $36.4 \%$ ), and Artisans (males $82.4 \%$ and females 17.6\%). In addition, most of the female S\&T graduates interviewed worked in University (57.1\%) followed by Polytechnics (29.8\%). These results suggest greater female participation in S\&T courses at the University and Polytechnics than in Colleges of Education, which agrees with the report of Fox (1998) that more women are pursuing higher degrees in the natural sciences and engineering than ever before.

Most $(81.5 \%)$ of the Heads of departments of the female S\&T graduates in the tertiary institutions attested that they do not have any female S\&T graduate working in non S\&T positions. Only $18.5 \%$ of the respondents said that some of the female graduates work in non S\&T positions. This result throws light on the occupational engagement of the female S\&T graduates. It shows that most of these female graduates employed in tertiary institutions are engaged in S\&T based occupations.

\section{Female Science and Technology Graduates Responses on Employments in Tertiary Institutions and Firms}

Table I shows the various departments where FSTG are employed both in tertiary institutions and in firms. The largest proportion (32.3\%) was employed in Research and Development (R\&D). R\&D and Administration have relatively closer proportions of women. The large number of FSTGs engaged in administrative duties is probably due to women functioning in supervisory and managerial posts. About $8.1 \%$ work in Planning and Documentation. The proportion of women employed in Quality Control (QC) and Manufacturing are $11.8 \%$ and $4.9 \%$ respectively. It seems the three major areas of employment with high number of FSTG are i) Administration (37.5\%) including Planning and Documentation, ii) R\&D (44\%) which includes QC and teaching (9.4\%). Only a small proportion (4.9\%) works in Manufacturing and $3.4 \%$ in Accounts. The small number in Finance and Accounts contradicts the general belief that many engineers are employed in the financial industry.

\begin{tabular}{lll}
\hline Sectors of Employment of FSTG & Frequency & Percent (\%) \\
Manufacturing/production & 58 & 4.9 \\
Quality control & 141 & 11.8 \\
Administration & 351 & 29.4 \\
Research and development & 385 & 32.3 \\
Planning and documentation & 97 & 8.1 \\
Accounts/finance/supply & 40 & 3.4 \\
Medical & 6 & 0.5 \\
Academics & 112 & 9.4 \\
Security/solicitors & 3 & 0.3 \\
\hline
\end{tabular}

Table I. Sectors of Employment of Female S\&T Graduates

Further information provided by employers in firms indicated that most of the organizations had the highest number of women working in Administration sector (36\%), some $22.6 \%$ worked in the Accounts and audit section, and $13.6 \%$ are employed in the Laboratory, while Research and Technical units had about $11.7 \%$. About $5 \%$ of the women engaged in manufacturing work. Public relations unit has about $11.3 \%$ of the FSTGs. This result suggests that most of the organizations visited, about $30 \%$ of the female staff are employed in S\&T activities (manufacturing, laboratory, Research and Technical), while non S\&T sections of the organizations have a higher number of women.

Of the non S\&T departments in which FSTGs were employed (Table 2), Administration has the highest proportion (43.3\%) followed by the financial units accounts and audit (33.4\%) and public relations unit in the third position with $22 \%$ and other $1.4 \%$ e.g. Library. The FSTG were asked why a large number of them took up 
non S\&T employment, about $40 \%$ indicated that at the time of employment, there were no alternative offers. About 19\% wanted a change in career, while a similar proportion was of the opinion that career in S\&T was too demanding. Some $22.7 \%$ of the respondents abandoned S\&T employment for greener pastures or more attractive opportunities. It is interesting to note that just about $0.2 \%$ changed jobs or took up non S\&T employment on

\begin{tabular}{lll}
\hline Departments & Frequency & Percent (\%) \\
Administration & 420 & 43.3 \\
Accounts & 203 & 20.9 \\
Audit & 121 & 12.5 \\
Public relations & 213 & 21.9 \\
Others & 14 & 1.4 \\
\hline
\end{tabular}

Table 2: Non S\&T Departments where Female S\&T Graduates Work domestic grounds. However, the $40 \%$ of FSTGs that are engaged in non S\&T employment on the grounds that there were no vacant $S \& T$ positions may actually be due to domestic issues i.e. moving to a town where the spouse is employed and would for the sake of seeing all member of the family being together, take up any available employment.
Many of the FSTGs experienced delay in getting employment for various reasons. About $23 \%$ went for higher degrees on graduation, while some $36.8 \%$ indicated there were lack of suitable positions where they lived. About $15.5 \%$ of the respondents indicated that the class of degree was a limiting factor and lack of funds hindered some $21.8 \%$ from gaining immediate employment by not being able to travel to attend interviews. Respondents indicated that they observed gender discrimination during interviews or while seeking employment. Lack of suitable employment suggests that respondents lived in locations with little or limited S\&T job opportunities. Further analysis indicated also that these women were married and this restricted them to such locations as commitment to their spouses.

The FSTGs were asked if they knew of any of their colleagues working in non S\&T employment, $34.6 \%$ indicated a Yes and $65.4 \%$ a No. Of those who were aware, about $46.5 \%$ of the respondents knew between I-5 female friends or colleagues employed in non S\&T organizations. Some $30 \%$ of the respondents each knew about 10-15 FSTG working in Non S\&T establishments, while about $24 \%$ knew either more than 16 or more FSTG engaged in non S\&T tasks.

Some S\&T organizations did not have any female working in S\&T departments. Some of the reasons given by the respondents include: distraction by reproductive activities (31\%); lack of skill (24.1\%); the strenuous nature of the job to be done (22\%); and inadequate qualifications (22\%). Some of these excuses are discriminatory in nature and should attract attention. This suggests that reproductive activities of the female work force are yet to be seen as a positive contribution to socio-economic development.

\section{Employment Challenges}

Above $95 \%$ of the FSTG attested that they did not have prompt employment after graduation. Some of the reasons given for this include: lack of funds for logistics (21.8\%); limitation by the class of degree (15.5\%); desire to acquire further degree (22.8\%); poor government economic policy (1.7\%); domestic responsibility $(0.4 \%)$; gender discrimination $(0.1 \%)$ and lack of suitable employment $(36.8 \%)$. Only very few $(0.8 \%)$ indicated that they had no hindrance to prompt employment. It is hoped that the recently introduced entrepreneurial courses into the tertiary institutions curriculum would reduce the problem of unemployment.

\section{On the Job Training}

Responses on how often FSTG were considered for inservice training showed that $34.3 \%$ attended a training at least once a year. Some $21.6 \%$ indicated that they participated between 2 to 4 times in a year. However, a large proportion of respondents $(37.9 \%)$ said they had never been on any training programme since they were employed. A few of the respondents $6.1 \%$ reported 
occasional participation at training programs. These include those whose training were not frequent but as determined by the management. Further analysis showed that majority of respondents who had a poor record of in-service training were employed in private organizations. The benefits of in-service training cannot be over emphasized as it refreshes old knowledge, while getting acquainted with new practices resulting in better output.

\section{Performance Challenges}

For the married respondents, performance of their reproductive functions clashed with their jobs mainly in two dimensions i) about $66.6 \%$ indicated inability to travel and ii) $33.3 \%$ identified insufficient time for research by FSTG working either in academic institutions or in R\&D laboratories. A few of the unmarried respondents complained of serious discomfort during the monthly menstrual cycle, which sometimes necessitated time off work.

FSTG were asked if assignments were given or distributed on gender basis, less than a third (i.e. $28.8 \%$ ) said yes but the majority (7I.2\%) indicated a No, implying that the FSTGs were given equal opportunity to prove their worth even in tasks such as welding, automobile repair and assemblage, wood and woodwork processing, going on night shift and field work.

Heads or immediate bosses of the respondents were asked to rate the performance of the FSTG staff compared to their male counterparts in the following areas: number of articles published, qualification, experience, and ability to meet set target and interpersonal relationships. About $29.1 \%$ of the respondents were ranked between $81-100 \%$, $38 \%$ had $61-80 \%$, and $19.7 \%$ got $41-60 \%$, while $13.2 \%$ had less than $40 \%$. This shows that the majority of the FSTGs performed satisfactorily at work (i.e. above average).

Apart from the tertiary or research institutions where number of published articles is a promotion criterion, the criteria for promotion in most other organizations are similar. They include: academic qualification (27.7\%), number of years at a position (20.9\%), ability to meet set target $(20.9 \%)$ and leadership quality (15.1\%). Considering the criteria for promotion for both male and female scientists and engineers in tertiary institutions, and comparing the number of female promotion to men (Figure 2), one could conclude that there was no significant difference in the number of promotions especially since there were more males than females in the departments. However, $56.9 \%$ of the respondents felt that the reproductive activities of women affected their job performance as it resulted in lower productivity (32.5\%), domestic concerns $(27.5 \%)$, reduced time spent at work $(30.8 \%)$ and the vacuum created $(9.2 \%)$ when they go on maternity leave. Nevertheless, $21.8 \%$ of the respondents felt that jobs that might be affected by women reproductive role in an organisation can be rescheduled and majority (63.6\%) of the respondents were also of the opinion that women generally are efficient and committed to work and therefore reproductive roles do not affect their job performance. This may account for the reason why $88.4 \%$ of the employers went in favour of promoting further employment of women.

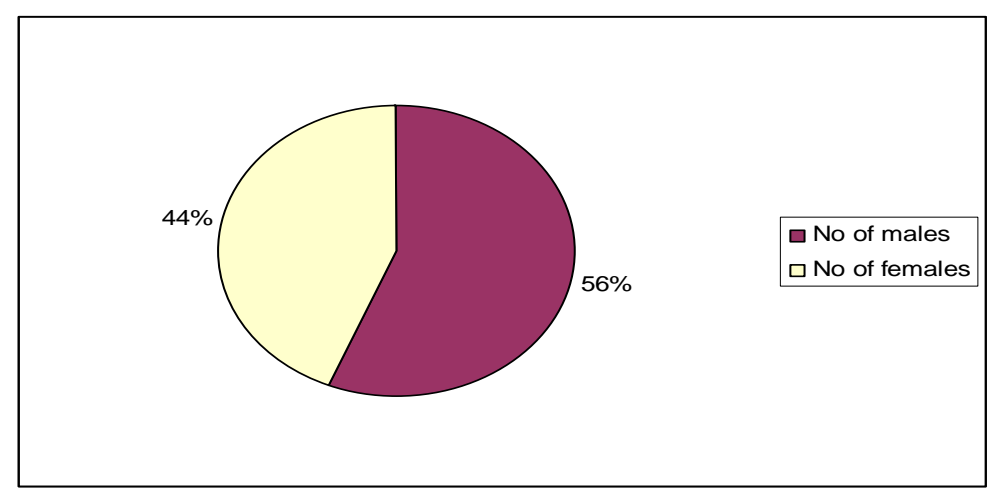

Figure 2. Staff Promotion for a Span of Five Years

A high percentage (88.4\%) of employers said that they would promote further employment of women because they are very efficient (47.5\%). Other reasons given for promoting further employment of women included gender 
equity (20.2\%); professional contribution (13.1\%); contribution to family income (10.4\%); and possession of equal capability as men (7.7\%). However, others (28.6\% each) were of the opinion that women should not be employed because they are physically challenged, create a vacuum/workload for others, and that they spend time away from work. These contrary views cannot be said to be applicable to women alone, but also to men.

The study verified the availability of crèche facilities in the place of work, which was an instrument proposed for the enhancement of job performance of female S\&T staff. More than half $(52.5 \%)$ of the respondents said there was no provision for crèche in their work place and only $47.5 \%$ said that they had it in their organisation. Some of the reasons given for not having crèche facilities in some organisations included the absence of policy to the effect (37.9\%), lack of fund and lack of female workers (13.8\% each), non-conducive environment (12.1\%) probably due to the nature of the business. It is our view that availability of crèche facilities in the work place could help to promote job performance as both male and female staff would spend the time that would have been spent on caring for children in the office knowing well that their children are well taken care of.

\section{Enhancing Female Participation in S\&T}

The respondents made the following suggestions that could enhance female participation and performance in S\&T.

\section{Reproductive Roles}

In Nigeria, reproductive roles are same of the excuses given by certain firms for not encouraging female participation. The study thus verified some of the policies that existed in the sampled tertiary institutions and firms on the reproductive roles of women. In the tertiary institutions, policies included maternity leave without pay (3.5\%), half day at work for 3 months after maternity leave (9.9\%), maternity leave with pay (45.0\%), permission to pick up children from school during office hours (22.0\%), release from work to stay with sick child (17.4\%), late working hours $(2.1 \%)$. This result shows that employers in tertiary institutions in Nigeria give consideration to the reproductive years of female S\&T staff by allowing them to go for maternity leave with pay and also to attend to the child after birth. Only very few (3.5\%) institutions (probably private ones) give maternity leave without pay.

\begin{tabular}{ll}
\hline Policies & \% Response \\
\hline Maternity leave without pay & 3.5 \\
Half day at work for 3 months after maternity leave & 9.9 \\
Maternity leave with pay & 45.0 \\
Permission to pick up children from school during office hours & 22.0 \\
Release from work to stay with sick child & 17.4 \\
Late working hours & 2.1 \\
\hline
\end{tabular}

Table 3. Policies in Tertiary Institutions on Reproductive Roles

\begin{tabular}{lll}
\hline S/NO & Policies & \% Response \\
\hline & & \\
I. & Maternity leave without pay & 12.9 \\
2. & Hal'f day at work for 3 months & 46.7 \\
3. & Maternity leave with pay & 13.3 \\
4 & Permission to pick up children after school & \\
\hline
\end{tabular}




\begin{tabular}{lll}
\hline 5. & Release from work to stay with sick children & I4.I \\
6. & Late working hours & 5.2 \\
7. & Maternity leave for months & 1.5 \\
8. & Financial Assistance & 0.7 \\
\hline
\end{tabular}

Table 4. Policies in Organisations on Reproductive Roles

The policy on reproductive roles of women at their work places according to Table 2 shows that, relatively, most women $(46.7 \%)$ have privileges of putting the home front in order during their reproductive years. These include, among others, having payments during their maternity leave as $12.6 \%$ of the organizations give half day for three months after resumption of leave, opportunities to their female employees to stay with sick children (14.1\%) and permission to pick up children after school among others (13.3\%).

Comparing the responses from both tertiary institutions and organizations, majority (36.6\% and $38.9 \%$ respectively) of the employers feels that the reproductive years of women should be appreciated as a normal life process and therefore there should be allowance for flexible schedule during the period $(28.5 \%$ and $32.4 \%$ respectively). In addition, suggestions were made that there should be provision of day care facilities beside place of work (33.7\% and $26.9 \%$ respectively). Other suggestions offered to enhance the performance of women on their job in tertiary institutions include commendation and special medical welfare package for women. In the firms, respondents suggested that women should emulate men in training and development; they should also be determined and let their impact be felt.

\section{Gender Friendly Policies}

In order to enhance the performance of the female workforce, the FSTGs themselves indicated /highlighted some gender friendly policies adopted by their organizations. About $50 \%$ of the respondents had enjoyed maternity leave with pay, and $22.9 \%$ were given time to pick kids from school in the afternoons. Working for half a day for three months after the maternity leave was indicated by $15.4 \%$, while $11.8 \%$ indicated that they went on maternity leave without pay. Majority of those who went on maternity leave without pay were employed in the private sector and worked either in manufacturing or
R\&D units of these establishments. On the other hand, respondents who had enjoyed maternity leave with pay or half day were employed in government agencies or academic or research institutions. This result calls for a closer look at the working conditions in private organizations vis-à-vis adoption of policies that foster gender friendly environment.

\section{Discussion}

The study assessed employment pattern of females trained in S\&T in Nigeria and implications for their participation and performance in S\&T occupations. Employment pattern revealed that most FSTGs employed in tertiary institutions and research institutions were engaged in S\&T based occupations. However, it was observed that as qualifications and degrees got higher, fewer women were noticed at the higher levels. Thus, it becomes apparent that barriers to recruitment, retention and progression in Science, Engineering and Technology (SET) upgrade in tertiary and or research institutions often act to discourage women who wish to pursue academic careers. Such barriers for the married women may include: their reproductive functions clashing with their jobs mainly on two dimensions which are their inability to travel and insufficient time for research. Such challenges could be eased by the Federal government policy on maternity leave coupled with planning and management of the reproductive phenomenon by the FSTGs.

However, in corporate firms, most of the FSTGs work either in administration, finance or R\&D departments. In addition, a large proportion takes less paying non S\&T jobs for domestic reasons and lack of suitable vacancies. This is gross under-utilization of human resource. The initiative by the Federal Government to create more jobs through industrial development should be encouraged, as this would create more employment opportunities for women. In addition, the Federal Government should initiate 
affirmative actions to employ more women in the S\&T sector as has been done by some countries such as South Africa, Britain among others.

Some S\&T organizations did not have any female working in S\&T departments with excuses such as distraction caused by reproductive activities, lack of skill, strenuous nature of the job to be done and inadequate qualifications. Most of these excuses are discriminatory in nature and should attract attention. This suggests that reproductive activities of the female workforce are yet to be seen as positive contribution to social and economic development of the nation. Be that as it may in some organizations, some others adopted some gender friendly policies which include: maternity leave with pay, time to pick kids from school in the afternoons, working for half a day for three months after resumption from maternity leave and maternity leave without pay. It is observed that majority of those who went on maternity leave without pay are employed in the private sector and are working either in the manufacturing, production or R\&D units of these establishments while respondents who have enjoyed maternity leave with pay or half day are employed in government agencies or academic or research institutions. This result calls for a closer look at the working conditions in private organizations vis-à-vis the adoption of policies that foster gender friendly environment. Working conditions have to be improved by elongating maternity leave and also by having flexible working hours to accommodate the reproductive period in a female employee's life, while they systematically contribute their skills and potentials to economic growth and development of the nation.

Domestic issues and responsibilities constitute primary challenges that female S\&T professionals face which affects their performance and progress at work. Employers of labour need to create an environment that is conducive for the reproductive years of their female S\&T workforce. Child bearing and rearing are positive contributions the female make towards providing human resource and should therefore not be a limiting factor in the advancement of women. Many developed nations have low birthrates because the women do not want their reproductive roles to hinder their professional progress and now the government of some of these nations pays the women who choose to give birth as a form of encouragement in order to boost their population growth.
Also, experience as a recruitment criterion should not be a rigid criteria for women as in some tribes of the country most of their women due to early marriage, have had to finish their reproductive years before going back to school, thus creating a wide gap in age between their contemporaries with whom they graduated.

\section{Policy recommendation}

a. Provision of crèche facilities would go a long way to enhance the job performance of the FSTGs during their reproductive years.

b. Enlightenment of the society on the need for a change of attitude to gender roles, as this would affect the acceptability of women who venture into the so called 'male dominated' professions.

c. The Federal Government should initiate affirmative actions to employ more women in the S\&T sector as practised by some countries such as South Africa, Britain, among others. Also, the experience, recruitment criteria should be made flexible for women especially in the Private and Financial sectors.

d. Both the government and professional S\&T bodies need to pay closer attention to the working conditions of women for example by elongating maternity leave and instituting flexible working hours to enable women contribute their quota to the economic development and growth of the nation as it is done in developed countries.

e. The network for women engineers and managers should be encouraged to boost professionalism and knowledge sharing for female in their careers. This will encourage linkages among organizations both locally and internationally. Professional women organizations can help in this regard. There is also need to showcase successful female scientists and engineers and create a culture of mentorship and role models.

f. Private organizations should be mandated by both the government and professional engineering bodies like Nigerian Society of Engineers (NSE), Council of Registered Engineers (COREN), Nigeria Computer Society (NCS) among others to ensure retraining of staff of their establishments. 


\section{Acknowledgement}

The researchers are grateful to the Federal Ministry of Science and Technology and the National Centre for Technology Management- Nigeria for the sponsorship provided for this survey.

\section{References}

ARMOUR, N. (2003) Changing Lanes: Women in Science and Technology, An initiative of the Hypatia Project, Halifax, Nova Scotia Canada.

http://www.gasat-international.org/conferences/GII

Mauritius/proceedings/proceedings\%206.doc (assessed 23 August 2008)

AUSTRALIAN SCIENCE AND TECHNOLOGY HERITAGE CENTRE (2003) Where are the women in Australian Science, http://www.austehc.unimelb.edu.aul wisaabout.html (assessed at 29th January 2009)

ELLIS, P. (2003): Women in Science-Based Employment: What Makes the Difference? Bulletin of Science, Technology \& Society, Vol. 23 (I), I0-I6 (2003)

FOX, M.F. (1998) Women's Participation in the Public Sector Science, Engineering and Technology Workforce. http://www.dst.gov.za/publications/reports/part 02.pdf (assessed 23 August 2008)

HUYER, S., Westholm, G. (2000) UNESCO Toolkit on Gender Indicators in Engineering, Science and Technology, Gender Advisory Board, UN Commission on Science and Technology for Development

KISHORE, L. (2008) Girls, women in science \& technology education Merinews, http://www.merinews.com/catFull.jsp ?articleID $=140417 \mathrm{~h}$ (assessed 29 ${ }^{\text {th }}$ January 2009)

MARASCO, C. A. (2005) Mentornet Supports Women in Science. Career and Employment Volume 85(20) PP 55-56, 58,60

MCGREGOR, E., Harding, S. (1996) "Science by whom?" In World Science Report 1996. Paris: UNESCO. 